\title{
O uso da Internet como espaço terapêutico
}

Nara Beatriz Kreling da Rosa*

Resumo: O presente artigo trata de um comportamento social entre os adolescentes que vem se tornando cada vez mais crescente, o uso da Internet - blogs, Facebook, Orkut - como terapia virtual em grupo. Adolescentes e pré-adolescentes têm usado os espaços virtuais para escancarar sentimentos, queixas, dar depoimentos e conselhos em busca da diminuição de suas ansiedades, frustraçốes e incompreensões. A priori, as formas de buscar ajuda deveriam ser presenciais, apoiadas na família, nos amigos e em alguns casos em profissionais especializados. $\mathrm{O}$ artigo apresenta a visão de especialistas e estudiosos sobre o novo fenômeno, procurando apontar o papel da escola e da família. Como exemplo desse fenômeno social, enfoca o comportamento dos adolescentes que se automutilam e recorrem as redes sociais para aliviarem sua tensão emocional.

Palavras-chave: Internet; Adolescentes; Automutilação.

Abstract: This paper deals with social behavior among teenagers that has been growing bigger: the use of Internet - blog, Facebook, orkut -, as a collective virtual therapy. Teenagers and preteenagers have used virtual space to show their feelings, complaints, and give evidence and advice in order to reduce their anxieties, frustrations and incomprehension. A priori they should seek help in person with their family and friend support, and sometimes with a specialized professional. This paper presents the points of view of specialized professionals and researchers on that new phenomenon, and points out the school and family

* Orientadora Educacional do Projeto Amora no Colégio de Aplicação/UFRGS. Mestre em Letras. Especialista em Aconselhamento Psicológico e em Psicodrama. Formação em Coordenação de Grupos. E-mail: narabea@cap.ufrgs.com 
roles. As an example of such social phenomenon it focus on the behavior of teenagers who mutilate themselves and resort to social webs to ease off their emotional tension.

Keywords: Internet; Teenagers; Self-Mutilation.

\section{Introdução}

As redes sociais existem para proporcionar meios diferentes e interessantes de comunicação e para facilitar a interação. Esse é o objetivo dos seus criadores. Certamente, no entanto, quando as idealizaram não imaginaram o complexo desdobramento do seu uso.

Cada vez mais, independente da classe social a que pertencem, adolescentes têm dominado as redes sociais elegendo-as como um espaço para interagirem com outros adolescentes. Em 2010, o Comitê Gestor da Internet no Brasil anunciou, a partir de pesquisa realizada, que o uso da Internet nos lares havia superado o seu acesso aos dos locais públicos, segundo publicou a revista Viagem e Turismo em maio do mesmo ano. E o avanço havia ocorrido nas distintas classes sociais. Na população com renda entre 2 a 3 salários mínimos, por exemplo, o aumento da penetração da Internet foi de 95\%. Sem dúvida, o acesso em locais reservados, como em casa, em seus quartos onde não são vigiados, os adolescentes se sentem mais livres para expressarem conteúdos que antes não ousavam manifestar.

Vários sites de rede social operam mundialmente. Alguns vão caindo em desuso como o Orkut, outros vão ganhando força. Entre os jovens brasileiros o Facebook e o Twitter são os mais acessados. No entanto, são especialmente nos blogs que se podem encontrar escritas escancaradas de seus sentimentos, cujas narrativas de si mesmos são visíveis consultórios confidenciais. Já é possível a criação de redes sociais exclusivas, ou seja, qualquer um pode ter sua própria rede social voltada para um público e tema específico. E um exemplo disso o Tumblr, 
site usado preferencialmente por aqueles que sentem prazer em escrever fofocas.

As pesquisadoras Camozzato e Garbin (2010), interessadas em investigar "como são tornadas possíveis escritas na internet que demonstram o ódio a pessoas gordas?”, consideraram que o Orkut constitui-se como um laboratório para produção de identidades e subjetividades, em que os corpos de cada um também se encontram dentro dessa discussão.

Bem mais do que fazer novas amizades, manter contatos, fazer pesquisas acadêmicas, discutir temas, pertencer a comunidades, trocar fotos, os sites das redes sociais têm servido para os adolescentes exporem seus conflitos mais íntimos. As páginas da web acabam por funcionar como verdadeiros settings terapêticos e também como fonte de pesquisa para especialistas interessados conhecerem o assunto. Na Internet, tornam-se possíveis conhecer escritas que demonstram compartilhamento de sentimentos de depressão, de solidão, de incompreensão, de frustração, de ódio e, quase em tempo real, de pedidos de ajuda. Uma espécie de consultório psicológico de terapia virtual de grupo, sem hora marcada, via rede social. Mas até que ponto tais práticas funcionam? Do ponto de vista dos estudiosos desse comportamento social há os que se beneficiam apenas com os comentários, com as frases de efeito, com os elogios que suas queixas e lamúrias despertam. Os que se sentem isolados buscam um grupo ou uma comunidade para se identificarem já que o grupo ajuda a potencializar as habilidades interpessoais, mas para isso precisam divulgar o que sentem e que o fazem. Ainda, para os que se sentem incompreendidos, chatos, desassistidos, tristes - sentimentos comuns entre os adolescentes - as páginas da Web prestam-lhes o serviço de darem a atenção da qual reclamam ao mesmo tempo em que estão livres da crítica das pessoas mais próximas, que poderiam condenar seus atos e pensamentos. As redes sociais, dessa forma, são como uma companhia, que os acolhe já que fora dela não conseguem exercer a socialização e receber a compreensão desejada. Depoimentos virtuais conferem o sentido de 
ajuda recebido pelo usuário que postou a seguinte mensagem: "... essas frases poderosas funcionam. No momento certo, fazem muita diferença. Conheço inúmeros casos que comprovam isso. Já aconteceu até comigo". Pelo simples fato de expressarem-se por escrito, de postar suas queixas, mesmo que não recebam um retorno, usuários afirmam que essa prática funciona.

As ferramentas das redes sociais, essencialmente entre os adolescentes, configuram-se como meios de amplificar e saciar os ideais de relacionamento e de identificação. Existe uma sedução anônima, e também existe 'um outro' que se deixa seduzir. Existe um sonho de ser outra pessoa, um desejo de fugir do que the falta no cotidiano, uma falta psíquica resultante das interações superficiais e egoístas dos tempos atuais. Daí se pode inferir sobre o verdadeiro fascínio que os jovens têm pelas redes sociais.

A apropriação desses serviços repercute na vida cotidiana dos adolescentes de tal forma que acaba por exercer neles um certo domínio, cuja necessidade de estarem conectados é tamanha que, em alguns casos, ocupa a maior parte do seu tempo. Em uma recente atividade pedagógica realizada com adolescentes de 12 a 14 anos, no Colégio de Aplicação de Porto Alegre ${ }^{1}$, na qual os alunos deveriam registrar por um dia a sua rotina alimentar, horas de sono, atividades físicas e tempo de uso diante aparelhos eletrônicos, os resultados apontaram que muitos desses estudantes deixavam de se alimentar para ficarem postando mensagens em redes sociais. Ao tomarem consciência de como distribuíam seu tempo deram-se conta de que se alimentavam pouco ou de maneira inadequada e que isso se dava não por falta de tempo, como até então acreditavam, mas pelo excesso de horas que ficavam conectados. Os dados também mostraram que grande parte desses alunos dormia pouco, aquém do número de horas indicado para sua faixa etária e ainda que estendiam o uso da Internet para interagir com seus colegas ou amigos virtuais desconhecidos, para além das 24 horas.

Atividade Integrada 'Alimentação' realizada com a turma AII/2012 do Projeto Amora. 
Os problemas são vários e o perigo também: salas de batepapo, cyberbullying, acesso a conteúdos inapropriados, desinformação sobre as consequências de se exporem em redes sociais, crimes cometidos sob a falsa impressão do anonimato. A inabilidade de pensamento crítico dos adolescentes pode colocá-los em risco. Os conteúdos a que têm acesso suscitam sua curiosidade e, conforme seu grau de fragilidade podem levá-los a cometerem atos arriscados sugeridos pelo seu interlocutor.

\section{O tema da automutilação nas redes sociais}

Blogs atuais tratam do tema da automutilação. Um distúrbio caracterizado por ser um fenômeno difícil de tratar e que os especialistas dizem que tem aumentado entre os adolescentes, colegiais e até mesmo entre os mais novos. No Brasil não existe uma estatística oficial, mas só no Orkut se pode encontrar mais de 20 comunidades com esse tema, em média de 500 participantes. No Hospital das Clinicas/SP, o único centro oficial do país com tratamento nessa na área da psiquiatra, o número de atendimentos tem aumentado constantemente. Estudiosos acreditam que o aumento de atos de autolesão nos adolescentes se deve em parte às redes sociais, que espalham informações a respeito desse tipo de comportamento e que ensinam a agredir seu corpo quando se sentem sós e deprimidos. Consideram que as redes incitam pessoas que de outra forma não teriam tanta informação a respeito desse tipo de comportamento. Tais concepções tomam por base postagens como a que segue: "Este post foi tirado do meu blog particular, referente há um fato ocorrido no último ano com um amigo e achei que seria interessante dividir com vocês".

A automutilação, frequentemente, começa com as mudanças emocionais intensas da pré e do começo da adolescência, mas pode persistir. Tão logo o comportamento seja detectado e tratado, dizem os especialistas na psiquê humana, provavelmente mais rápido o problema termina, sem deixar cicatrizes físicas. 
Alguns ídolos e celebridades têm contribuído para influenciar nesse ritual. Os mais jovens fazem referência à cantora Demi Lovato que sofreu bullying, anorexia e revelou em um vídeo no Youtube que havia se automutilado. Na Internet, adolescentes postam fotos de seus cortes, escrevem sobre como se cortam e como se sentem após realizarem essa nova versão de escarificação. Relatam que, usualmente, seus alvos são os braços, pernas, barriga e mãos por serem de acesso fácil e por serem escondidos dos pais e professores. Nas escolas, o assunto estende-se, mesmo em meio a períodos de aula e nos horários de recreio quando essa temática toma conta do pensamento e das conversas em fechados grupos de estudantes.

Mesmo que a automutilação não seja uma tentativa de suicídio como era vista no passado, e que o adolescente nunca tenha tido um pensamento suicida, pais, professores e amigos precisam estar atentos para os sinais desses comportamentos tendo em vista que são certamente uma resposta psíquica para algum desequilíbrio emocional. Além das preocupações de ordem emocional há o risco, sobretudo, de infecções. É preocupante porque para se cortarem ou se arranharem fazem uso de facas, agulhas, tesouras, estiletes, lâminas, objetos pontiagudos não esterilizados que são sugeridos entre eles, cujas imagens são exibidas na rede.

No divã das redes sociais, adolescentes dão algumas razões do porquê de machucarem seus próprios corpos. Em muitos casos há uma história de pais que não lhes dão o tipo de atenção que esperam e desejam. Frequentemente relatam que não existem adultos com quem poderiam conversar ou que não os aceitam da forma como são, levando-os então a uma baixa autoestima. $\mathrm{O}$ esforço dos jovens para que cuidem deles, que os outros se sintam culpados ou até mesmo que os deixem em paz, revertemse em comportamentos autoagressivos. Ser repreendido pelos pais por não ter cumprido alguma tarefa escolar ou doméstica parece ser um fato aparentemente insignificante para alguns pré-adolescentes. Para outros, no entanto, é motivo suficiente para desencadear um desequilíbrio emocional, machucando seus corpos em busca de alívio à tensão. 
Sob o ponto de vista dos especialistas, as causas da prática de autolesão em adolescentes residem geralmente na família. Pesquisas realizadas com famílias de automutiladores mostraram que é comum na conduta dessas famílias a supressão das emoções negativas. Sem saber como ou a quem recorrer para explicar seus motivos, as crianças crescem sem saber como expressar e lidar com sentimentos como o ódio, a tristeza ou a injustiça, direcionando então a dor emocional para seu corpo físico. $\mathrm{O}$ depoimento encontrado na Internet refere-se a essa afirmação: "minha mãe já viu uma vez e acha que não to fazendo mais isso... porém escondo os novos cortes".

Encarar o problema de frente requer no mínimo um acompanhamento sistemático por parte da família. Quase sempre o mecanismo de defesa adotado pelas famílias é o da negação, fazer "vista grossa" para o problema, não acreditar que é sério evitando buscar um atendimento com psicólogo ou psiquiatra. Em geral, consideram que é passageiro e que o simples fato de proibi-los de fazerem novamente o gesto de se cortarem os problemas estarão resolvidos. Ledo engano, quando os automutiladores param de se machucar fisicamente vem a sensação de vazio, dando lugar a outros transtornos comportamentais. Há casos, inclusive, que podem estar relacionados a distúrbio bipolar, distúrbios alimentares, pensamentos obsessivos ou comportamentos compulsivos. Mas, normalmente, a automutilação surge da culpa, começa como um impulso e se torna um hábito.

Para os leigos no assunto é difícil compreender o fenômeno. Como sentir alívio provocando lesão e dor em seu próprio corpo? Psiquiatras e outros especialistas acreditam que, ao se cortarem, os usuários liberam mais endorfina agindo no cérebro com uma sensação de bem-estar, que diminui a ansiedade e a tristeza. O cérebro estabelece uma ligação entre o falso alívio com os sentimentos ruins e o ato da mutilação, então anseiam por esse alívio na próxima vez que tiverem tensão. Dessa forma, a automutilação pode se tornar um comportamento compulsivo, que parece impossível parar, algo que acaba fugindo do controle 
da pessoa. Brigar, proibir ou se afastar não é uma boa estratégia de ajuda. Como em todos os casos de depressão ou desequilíbrio emocional somente uma verdadeira escuta, compreensão, aliadas ao tratamento especializado poderão encaminhar à cura. No Orkut foi encontrada a seguinte postagem:

Resolvi ir buscar na internet a resposta para que eu como amigo possa dar todo o apoio para que ele saia da depressão, para que possa não me surpreender com os seus atos, quando na madrugada receber suas ligações desesperadas. Acabo com isso aprendendo um pouco mais sobre o assunto, não da forma como gostaria, mas de certa forma de uma maneira para enriquecer meus conhecimentos, da forma como diz o ditado, vivendo e aprendendo. Embora ele tenha muitos bons amigos que também o estão ajudando, me sinto na necessidade de estar ao seu lado e ajuda-lo, pela proximidade de nosso convívio pela e cumplicidade de anos de amizade.

Assim, os pais sendo os responsáveis pela formação de seus filhos precisam estar atentos para os sinais desses comportamentos, não aceitá-los ingenuamente, sem questionar as explicações sobre as lesões tais como "eu me cortei sem querer com a faca"; "eu me arranhei na porta”. Quase sempre as pessoas mais próximas percebem por acaso os cortes, algumas vezes no banho, isso ocorre porque o ato é feito escondido e os adolescentes escondem os ferimentos sob longas calças e longos casacos, mesmo em dias quentes. Podem dar sinais indicativos também ao evitarem as atividades físicas. Depois de descobertos, mesmo que amigos ou pais se proponham a uma maior vigilância escondendo objetos que ferem, se o problema não for tratado de frente, o automutilador seguirá procurando objetos cortantes ou pontiagudos para se lesionar e se aliviar. Cacos de vidro, lâminas do apontador de lápis, pontas de lápis, fósforo são soluções de fácil acesso para atenuar a tensão psíquica.

Virtualmente, os automutiladores expressam que sentem uma sensação de conforto e bem-estar após se cortarem, que conseguem atenuar a dor interna transferindo-a para a externa. Seguem alguns relatos encontrados na Internet: 
1) “...a dor fisica é cócegas perto da dor espiritual.....qdo nos sentimos vazios...sensação de completa inutilidade.......ve não qr mais sentir aquela dor......e então vc pega algo cortante e se corta........... pronto!........as dores passaram e vc se sente melhor".

2)"Eu me sinto aliviado e menos ansioso após me cortar. A dor emocional vagarosamente se esvai em dor física”.

3 )"Foi quando numa depressão severa .. tbm tentei desabafar, sempre com as pessoas erradas como já foi dito aqui deu no que deu comecei a me cortar .. hoje em dia quando qualquer coisa me frustra apelo pros cortes".

Quando a rejeição por alguém importante, uma frustração por paixão não correspondida, assim como a sensação de estar errado ou ser culpado por algo de que a pessoa não conseguiu controlar, as redes sociais são o amigo mais próximo, o melhor ambiente de escuta, a forma mais rápida encontrada de aliviar o estresse. Um jovem de 13 anos, por exemplo, pode ir até a Internet e instantaneamente encontrar uma comunidade adepta a esse tipo de comportamento.

A conceituada revista de medicina The Lancet de Londres publicou uma pesquisa realizada em 2008, pela universidade australiana de Melbourne com 1.943 adolescentes, de 44 escolas. Entre os 149 adolescentes que revelaram automutilação, a maioria era menina. $\mathrm{O}$ estudo realizado também com participantes que se autoagrediam durante a adolescência foi considerado importante porque revelou um componente, até então não reconhecido, mostrou que a detecção precoce e tratamento dos fenômenos comuns da adolescência podem constituir um componente importante de prevenção de outros transtornos sérios quando adultos.

A socióloga Patricia Adler da Universidade do Colorado, nos Estados Unidos, em entrevista à revista Época afirmou, em contraposição a outros estudos, que as pessoas planejam seus ferimentos de forma racional e não de maneira impulsiva. Para ela, os casos são frutos da criação de uma cultura tolerante à autoagressão e pensam naquilo como uma válvula de escape para os dias tensos, disse ela. A estudiosa considera ainda que 
o fenômeno social "está virando uma tendência, uma moda. E competem para ver quem sofre mais, quem tem mais dor".

Um outro estudo recente realizado pela Universidade de Haifa, Israel, confirmou o que outras pesquisas já apontaram, ou seja, as redes socias por permitirem que adolescentes se expressem livremente e por ser um método fácil para a comunicação entre seus pares são uma maneira de liberar o estresse emocional. Mas o autor do estudo, o Ph.d. Meyran Boniel-Nissim, trouxe outra percepção para a questão. Para ele, no caso de "adolescentes problemáticos, manter um blog - diários virtuais - é a maneira mais eficaz na melhoria do desenvolvimento da autoestima sendo o registro diário comparado a um diário privado". Sem dúvida, expressar por escrito é uma dentre as diferentes formas de atenuar tensôes, mas colocar em rede online a sua fragilidade pode trazer consequências maiores do que o próprio problema. Há de se considerar que os adolescentes brasileiros são diferentes dos israelenses, dos americanos e outros. $\mathrm{O}$ contexto cultural deve ser levado em conta uma vez que as relações interpessoais nos lares brasileiros são permeadas bem mais pela afetividade e pelo contato físico do que em outras famílias. Desta forma, é questionável quando a pesquisa que está sendo divulgada pela Associação Americana de Psicologia, revela que os pesquisadores israelenses "acreditam que esse uso de redes sociais é especialmente adequado para adolescentes que passam a maioria do seu tempo on-line". Nos registros que divulgaram a pesquisa não foram encontrados aspectos que indicassem o papel da família no atendimento ao 'adolescente problemático'.

Também na Internet é encontrada a trilha sonora da música "Clarisse", da banda brasileira Legião Urbana, que fala sobre uma menina de 14 anos e de como ela foge dos problemas e das frustrações vivenciadas em seu dia a dia. Muito atual se for avaliado o número de vídeos que circulam na rede mostrando jovens que se mutilam. Contudo, é tranquilizador quando alguns especialistas afirmam que existe uma espécie de ciclo natural para o fim desse problema. As comunidades na Internet, da mesma 
forma que funcionam como um centro de compartilhamento dos problemas em que adeptos da autolesão querem encontrar outras pessoas como eles e falar sobre isso, também funcionam como um grupo de pessoas que se interajuda para largar o "vício" da automutilação. $\mathrm{Na}$ terapia virtual, pessoas informam formas de como agir para aliviar o estresse, tais como fazer simplesmente outra coisa por alguns minutos quando o impulso aparece; fazer com que as pessoas vejam a si mesmas não como vítimas, mas como agentes poderosos que conseguem fazer algo bom; substituir essa dor emocional por um comportamento emocionalmente saudável, entre outras sugestôes.

\section{Algumas Considerações Finais}

A internet oferece excelentes ferramentas de interação que têm sua importância na contemporaneidade, tornando-se fundamentais na vida das pessoas. Mas como em tudo, tem seus prós e contras. Toma-se como exemplo, uma página no Facebook. Ela não é privada. O que muitos usuários não sabem é que ao aceitarem os Termos de Uso do Facebook estão autorizando-o como proprietário exclusivo e perpétuo das informações e imagens que eles postaram. Os Termos de Uso reservam ao Facebook o direito a conceder e sublicenciar todo o "Conteúdo do Usuário". Considerando que muitos dos adolescentes do Facebook são internautas indefesos, são convertidos à intromissão nos seus assuntos privados e que de forma inconsciente podem acabar por ter seu comportamento controlado.

A educação e formação de crianças e adolescentes é função da escola, porém esse compromisso é primordialmente dos pais. Muitas vezes, perdidos em meio a tantas inovações tecnológicas, os pais sentem-se inseguros e confusos sobre quais os limites a serem impostos. Desconhecem os perigos reais que seus filhos podem estar correndo em virtude da exposição on-line, assim como desconhecem seus sentimentos, ansiedades e frustrações 
dos quais os professores há muito já identificaram. A falta de disponibilidade, de maturidade e até mesmo por negligência por parte dos pais, faz com que deixem a cargo da escola o que deveria ser de sua obrigação.

As redes sociais são, sem dúvida, uma fascinante invenção. Existem para que cada pessoa possa usá-las e escolher a sua melhor maneira de fazê-lo. Cada um a seu modo, serve-se delas dandolhe significado e sentido, levando a exibir sua subjetividade. Ao usá-las, os adolescentes apresentam uma variedade de vivências e nela tecem suas necessidades, por isso cabe aos pais alertar os filhos para os riscos de sua exposição, provocar o diálogo no sentido de procurar conhecer as suas reais necessidades emocionais e quando perceberem que a vivência na Internet é maior do que o envolvimento social e que outras atividades da vida do filho estão ficando de lado é hora de agirem. As famílias não podem deixar as redes sociais ocuparem o lugar que genuinamente é seu.

Por fim, é importante atentar sobre as transformações culturais de nosso tempo em que educadores e pais conscientes se veem obrigados a pensar e discutir sobre o impacto da tecnologia a cada vez que um avanço acontece. O que se espera é que as redes sociais não estejam a serviço de um abismo entre os adolescentes e suas pessoas mais próximas, mas sim para que pais, educadores e especialistas tenham conhecimento do que fazem e pensam os jovens em suas redes sociais na perspectiva de uma relação presencial de confiança e afetivo.

\section{Referências}

A AUTOMUTILAÇÃO VIROU MODA. Revista Época. Disponível em: $<$ http://revistaepoca.globo.com/Saude-e-bem-estar/noticia/2011/09/26/ patricia-adler-automutilacao-virou-moda.html>. Acesso em: 23 abr. 2012.

AUTOMUTILAÇÃO: CURANDO A DOR DA ALMA. Disponível em: $<$ http//www.ligacaoteen.com.br/saude/automutilação-curando-a-dor-daalma>. Acesso em: 03 jul. 2012. 
BLOGS AJUDAM REDUZIR ESTRESSE E AUMENTAR A AUTO-ESTIMA EM ADOLESCENTES. Revista Virtual Psicologado. Disponível em: <http://news.psicologado.com/psicologia-social/blogs-ajudam-areduzir-estresse-e-aumentar-a-auto-estima-em-adolescentes-segundopesquisa>. Acesso em: 18 jul. 2012.

BONIEL-NISSIM, Meyran. Pesquisa afirma que ao serem usadas como muro de lamentações as redes sociais ganham caráter de autoajuda. In: Revista Virtual Psicologado. Disponível em: <http:www.news.psicologado/psicologia-social>. Acesso em: 28 jun. 2012.

CAMOZZATO, Viviane; GARBIN, Elisabete. Corpos 'gordos' no Orkut: escritas sobre si e os 'outros'. In: COUTO, Edvaldo (Org.); ROCHA, Tania Brito. A vida no Orkut: narrativas e aprendizagens nas redes sociais. Salvador: Ed. EDUFBA, 2010. p. 189.

CUIDADOS com o Facebook. Recanto das letras. Disponível em: <http:// www.recantodasletras.com.br/artigos/>. Acesso em: 16 jul. 2012.

INSTITUTO DE ANÁLISE DO COMPORTAMENTO DE CURITIBA IACC. O aumento da onda de automutilação em adolescentes. Disponível em: <http://www.iaccsul.com.br/content-layouts/35-coluna-iacc/72-oaumento-da-onda-de-automutilacao-em-adolescentes $>$. Acesso em: 07 jul. 2012.

MUTILAÇÃO: meninas jovens são as maiores vítimas. Disponível em: $<$ http://vilamulher.terra.com.br/automutilacao-meninas-jovens-sao-asmaiores-vitimas>. Acesso em: 28 de jun. 2012.

VIAGEM E TURISMO. São Paulo: Ed. Abril, maio/2010, p. 61. 